\title{
The Temporal and Spatial Distribution of Volatile Organic Compounds (VOCs) in the Urban Residential Atmosphere of Seoul, Korea
}

\author{
Ashish Anthwal, Chan-Goo Park ${ }^{1)}$, Kweon Jung ${ }^{1)}$, Min-Young Kim ${ }^{1)}$ and Ki-Hyun Kim* \\ Department of Earth \& Environmental Sciences, Sejong University, Seoul 143-747 Korea \\ ${ }^{1)}$ Seoul Metropolitan Institute of Public Health and Environment, Seoul 137-734 Korea \\ *Corresponding author. Tel: +82-2-499-9151, E-mail: khkim@sejong.ac.kr
}

\begin{abstract}
Automobile emissions have caused a major hydrocarbon pollution problem in the ambient air of many cities around the world. This study was conducted to measure the pollution status of volatile organic compounds (VOCs) in some urban residential areas in Seoul, Korea. A total of 20 VOCs (11 aromatic and 9 chlorinated species) were identified at 4 urban residential sites in Seoul, Korea from February 2009 to July 2009. Comparison of total VOC (TVOC) concentration data indicated the dominance of the aromatic species with the maximum $(72.2 \mathrm{ppbC})$ at Jong Ro (JR) and the minimum at Yang Jae (33.4 ppbC). The peak concentration of TVOC occurred during spring at all sites with an exception at Gang Seo (GS), where it was recorded during winter. The distribution of individual VOCs at the study sites was characterized by high toluene concentration. A strong correlation of benzene was also observed with other VOCs and criteria pollutants at all sites (except $Y J)$. The overall results of this study suggest that vehicular emissions have greatly contributed to the increase in VOC pollution at all the study sites.
\end{abstract}

Key words: Urban air pollution, VOC, Aromatic, Vehicular, Residential

\section{INTRODUCTION}

Volatile organic compounds (VOCs) are an important group of air pollutants to be monitored in the ambient air, because of their versatile roles in environmental chemistry and the associated environmental impacts on the ecological systems. A number of VOCs are involved in tropospheric chemistry through the interaction with the $\mathrm{OH}$ radical or by the formation of photochemical oxidants (Wang and Zhao, 2008; Srivastava et al., 2006; Atkinson, 2000). Some VOCs are also reported to have toxic and carcinogenic health effects (Guo et al., 2004).

VOCs are released into the atmosphere from both biogenic (mainly vegetation) and anthropogenic sources. Anthropogenic sources include vehicle exhaust, gasoline evaporation, natural gas, and combustion of fossil fuels (Nguyen et al., 2009; Wang and Zhao, 2008). A large amount of VOCs are released in both a local and regional scale, while the patterns of their emissions vary depending on source characteristics. Emissions of aromatic hydrocarbons come from diesel and gasoline engine vehicles (Abrantes et al., 2004; Tavares et al., 2004; Broderick and Marname, 2002). In the urban areas, aromatic VOCs such as benzene, toluene, ethylbenzene, and xylene (collectively called as BTEX) constitute up to $60 \%$ of non-methane VOCs (e.g., Lee et al., 2002). Hence, BTEX compounds can be considered an indicator of organic compound pollution from road traffic (Hoque et al., 2008). The use of unleaded gasoline and diesel fuel has increased worldwide due to increases in traffic volume. As these fuels contain a large fraction of aromatic hydrocarbons, their monitoring in urban areas has become one of the prior tasks in air quality management.

The US EPA has classified benzene as a group A human carcinogen (US EPA, 1993), as leukemia has been observed in humans occupationally exposed to benzene. As toulene, xylene, and ethylbenzene can form secondary organic aerosol, they have also been the subject of several investigations (Cocker et al., 2001; Odum et al., 1997). The secondary organic aerosols can affect lung function (Seaton et al., 1995), while contributing to visibility degradation (Appel et al., 1985). Hence, a proper evaluation of traffic related contribution to regional VOC emissions is of great interest (Barletta et al., 2002; Kim et al., 2001).

As the capital of Korea, Seoul has an area of 605.5 $\mathrm{km}^{2}$ and a population of about 10.3 million with about 2.8 million motor vehicles (City of Seoul, 2010). As considerable amounts of airborne pollutants are postu- 


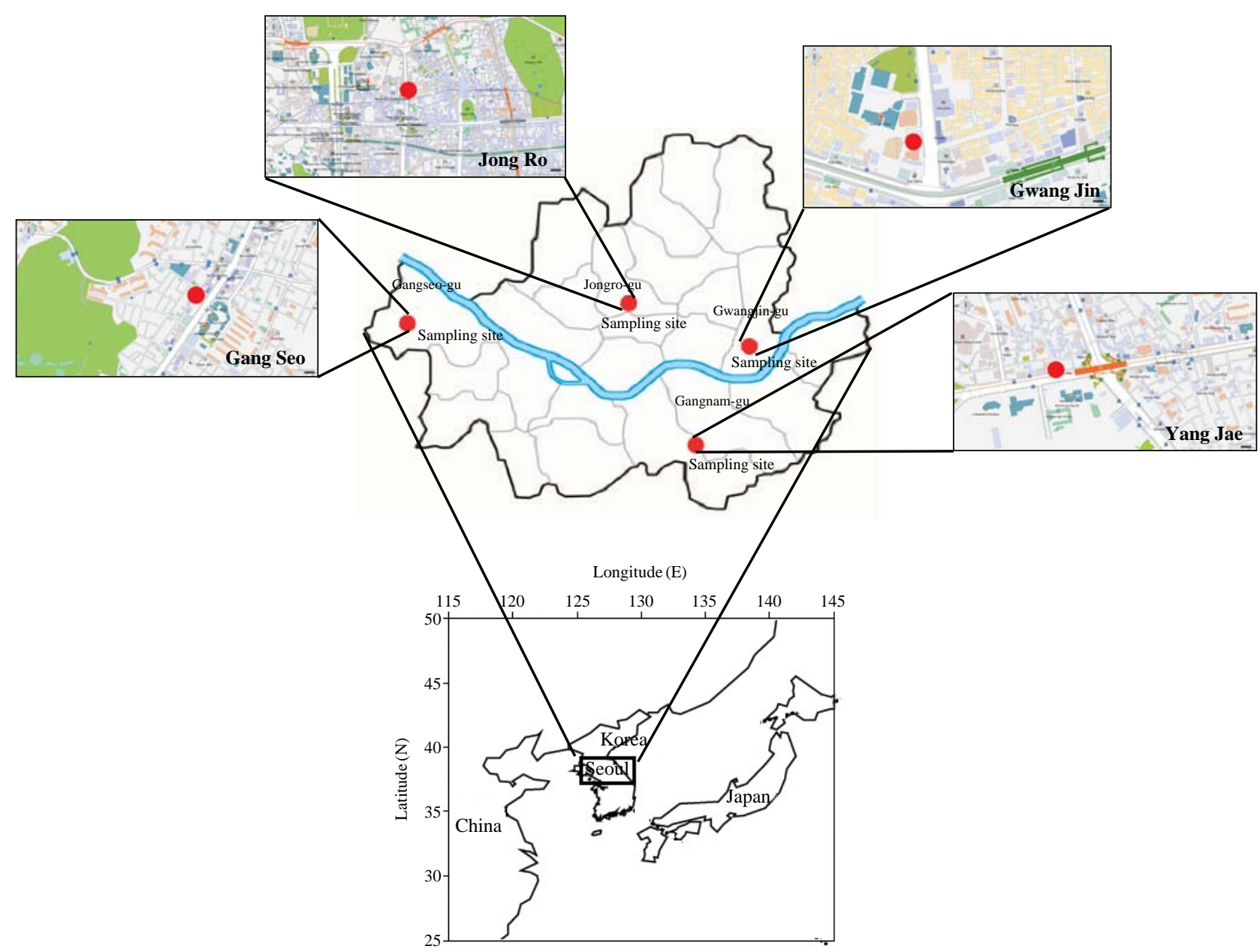

Fig. 1. Geographical location of four study sites in Seoul, Korea: Jong Ro(JR), Gwang Jin (GJ), Gang Seo (GS), and Yang Jae(YJ).

lated to be emitted, it is very important to describe the concentration, composition, sources, and behavior of VOCs for the development of their abatement strategies. The main objectives of this study were: (1) to describe the spatial and temporal distribution patterns of VOC in the ambient air; (2) to assess the status of VOC pollution in the ambient air of megacity; and (3) to identify the major factors and processes affecting the behavior of VOC in the urban air. For reader's reference, polycyclic aromatic hydrocarbons measured from the same study sites have been reported elsewhere (Anthwal et al., in press).

\section{MATERIALS AND METHODS}

\section{1 Field Site and Sampling}

In this study, the measurements of VOC in ambient air and the relevant environmental parameters were undertaken at four residential locations in Seoul which include Jong Ro(JR), Gwang Jin(GJ), Gang Seo (GS), and Yang Jae (YJ) (Fig. 1). GS might be affected due to road traffic, whereas GJ site was located near water purification plant under the direct effect of road traffic. All of these sampling sites represent air quality monitoring stations in residential areas where the basic air quality criteria have been monitored on a routine basis. None of the local emission sources were found near the sampling location. Thus, it can be postulated that the air samples collected at these sampling locations are influenced mainly by the common man-made activities in the urban area without any identifiable strong source activities. General aspects of these sampling sites have been described in our previous report of PAH study (Anthwal et al., in press).

The collection of VOC samples for this study was carried out from Feb to July 2009. During the study period, daily samples were collected for 30 minutes between 3-3:30 pm (over 3 consecutive days per month intervals). A list of VOCs selected and analyzed 
Table 1. Basic information of the volatile organic compounds (VOCs) monitored in this study.

\begin{tabular}{|c|c|c|c|c|c|}
\hline S. No & VOC species & Short name & CAS number & $\begin{array}{l}\text { Molecular weight } \\
\qquad \mathrm{g} \mathrm{mol}^{-1}\end{array}$ & Chemical formula \\
\hline \multicolumn{6}{|c|}{ Aromatic VOCs } \\
\hline 1 & Benzene & $\mathrm{B}$ & $71-43-2$ & 78.11 & $\mathrm{C}_{6} \mathrm{H}_{6}$ \\
\hline 2 & Toluene & $\mathrm{T}$ & $108-88-3$ & 92.14 & $\mathrm{C}_{7} \mathrm{H}_{8}$ \\
\hline 3 & Styrene & STY & $100-42-5$ & 104.15 & $\mathrm{C}_{8} \mathrm{H}_{8}$ \\
\hline 4 & Ethylbenzene & EB & $100-41-4$ & 106.17 & $\mathrm{C}_{8} \mathrm{H}_{10}$ \\
\hline 5 & m,p-Xylene & MPX & $108-38-3$ & 106.16 & $\mathrm{C}_{8} \mathrm{H}_{10}$ \\
\hline 6 & o-Xylene & $\mathrm{OX}$ & $95-47-6$ & 106.17 & $\mathrm{C}_{8} \mathrm{H}_{10}$ \\
\hline 7 & 1,2,4-Trimethylbenzene & 1,2,4-ТМB & $95-63-6$ & 120.19 & $\mathrm{C}_{9} \mathrm{H}_{12}$ \\
\hline 8 & Dichlorodifluoromethane & DCDFM & $75-71-8$ & 120.91 & $\mathrm{CCl}_{2} \mathrm{~F}_{2}$ \\
\hline 9 & Trichlorofluoromethane & TCFM & $75-69-4$ & 137.37 & $\mathrm{CCl}_{3} \mathrm{~F}$ \\
\hline 10 & Dichlorotetrafluoroethane & DCTFE & $76-14-2$ & 170.92 & $\mathrm{C}_{2} \mathrm{Cl}_{2} \mathrm{~F}_{4}$ \\
\hline 11 & 1,1,2-Trichlorotrifluoroethane & 1,1,2-TCTFE & $76-13-1$ & 187.37 & $\mathrm{C}_{2} \mathrm{Cl}_{3} \mathrm{~F}_{3}$ \\
\hline \multicolumn{6}{|c|}{ Chlorinated VOCs } \\
\hline 12 & 1,1-Dichloroethane & 1,1-DCE & $75-34-3$ & 98.96 & $\mathrm{C}_{2} \mathrm{H}_{4} \mathrm{Cl}_{2}$ \\
\hline 13 & Chloroform & $\mathrm{CF}$ & $67-66-3$ & 119.38 & $\mathrm{CHCl}_{3}$ \\
\hline 14 & Methyl chloride & $\mathrm{MC}$ & $74-87-3$ & 50.49 & $\mathrm{CH}_{3} \mathrm{Cl}$ \\
\hline 15 & Trichloroethylene & TCE & $79-01-6$ & 131.39 & $\mathrm{C}_{2} \mathrm{HCl}_{3}$ \\
\hline 16 & Perchloroethylene & PCE & $127-18-4$ & 165.8 & $\mathrm{C}_{2} \mathrm{Cl}_{4}$ \\
\hline 17 & 1,1-Dichloroethylene & 1,1-DCEY & $75-35-4$ & 96.94 & $\mathrm{C}_{2} \mathrm{H}_{2} \mathrm{Cl}_{2}$ \\
\hline 18 & Vinyl chloride & $\mathrm{VC}$ & $75-01-4$ & 62.498 & $\mathrm{C}_{2} \mathrm{H}_{3} \mathrm{Cl}$ \\
\hline 19 & 1,2-Dichloroethane & 1,2-DCE & $107-06-2$ & 98.96 & $\mathrm{C}_{2} \mathrm{H}_{4} \mathrm{Cl}_{2}$ \\
\hline 20 & 1,1,1-Trichloroethane & 1,1,1-TCE & $71-55-6$ & 133.4 & $\mathrm{C}_{2} \mathrm{H}_{3} \mathrm{Cl}_{3}$ \\
\hline
\end{tabular}

throughout this study can be extended to cover a total of 20 compounds (Table 1). They consist of eleven aromatic compounds including BTEX and nine chlorinated VOCs.

\subsection{Collection of Air Samples and VOC Analysis}

For the collection of VOC samples, adsorption trap was made using stainless steel tube. These tubes were packed with a solid sorbent Carbotrap 300 (a combination of Carbotrap C, Carbotrap B, and Carbosieve SIII). The former two types of Carbotraps are efficient to adsorb VOCs with $\mathrm{C}_{4}-\mathrm{C}_{14}$, while the latter Carbosieve is considered an optimal choice for low-weight VOCs with $\mathrm{C}_{2}-\mathrm{C}_{6}$. These sampling traps were conditioned for $1 \mathrm{~h}$ at $350^{\circ} \mathrm{C}$ with the constant supply of $\mathrm{N}_{2}$ at $50 \mathrm{~mL} \mathrm{~min}{ }^{-1}$. They were then sealed by both Swagelok fitting and PTFE ferrules. The collection of VOC samples on the carbotrap 300 was made from 3 PM for each measurement date for 30 mins duration with flow rate of $100 \mathrm{~mL} \mathrm{~min}^{-1}$ using a hand held pump (SIBATA $\Sigma 30$, Japan). The stainless steel tubes were stored at $4{ }^{\circ} \mathrm{C}$ and brought to the laboratory for analysis.

The VOC samples collected in adsorption traps were analyzed with the laboratory GC/MS system (Agilent GC/MSD, model 6890/5975B) via thermal desorption unit (Markes Unity Ltd., UK) on the following sequence: (1) thermal desorption of tubes at $280^{\circ} \mathrm{C}$ for 10 mins, (2) focusing of VOCs on cold trap at $-10^{\circ} \mathrm{C}$, and
(3) subsequent transfer of VOCs into the GC/MS system. The separation of VOC compounds was made by a capillary column (DB-1, $60 \mathrm{~m} \times 0.25 \mathrm{~mm} \times 1 \mu \mathrm{m}$ film thickness). The mass selective detector was operated in electron impact mode $(70 \mathrm{eV})$. The temperature program was conducted as follows: $40^{\circ} \mathrm{C}$ for $5 \mathrm{~min}, 50$ $230^{\circ} \mathrm{C}$ ramping at $7^{\circ} \mathrm{C} \mathrm{min}{ }^{-1}$, and $230^{\circ} \mathrm{C}$ for $10 \mathrm{~min}$. The flow rate of carrier gas (helium) was maintained at $1.3 \mathrm{~mL} \mathrm{~min}{ }^{-1}$. The method detection limits (MDL), if determined based on the instrumental detection limits for the VOC analysis, was in the range of $\sim<1.0 \mathrm{pg}$ $\mathrm{m}^{-3}$ or $0.24 \mathrm{ppb}$ ( 0.15 (vinyl chloride)-1.0 ng (m,pxylene) in absolute mass).

\section{RESULTS AND DISCUSSION}

\subsection{Distribution Characteristics of VOC}

A statistical summary of the relevant parameters measured at four urban locations during the study period is given in Table 2. Table 2 summarizes the sum concentration of aromatic and chlorinated VOC, criteria pollutants, and meteorological parameters measured during the study. In Fig. 2, concentrations of TVOC determined at four urban locations are compared along with the sum of aromatic and chlorinated VOC. The mean concentration of TVOC ( $\mathrm{ppbC}$ ) was seen in the order of 72.2 (18.1-149) at JR, 55.2 (12.1$157)$ at GJ, $59.0(18.6-165)$ at GS, and $33.4(9.8-123)$ 


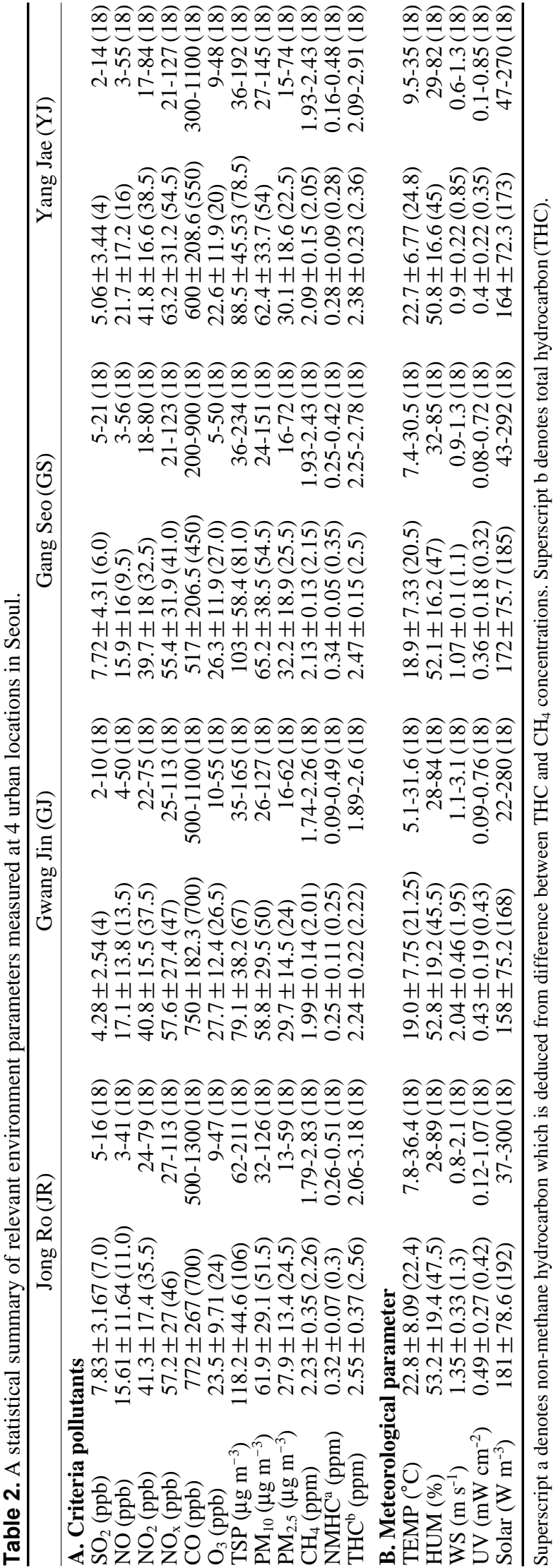

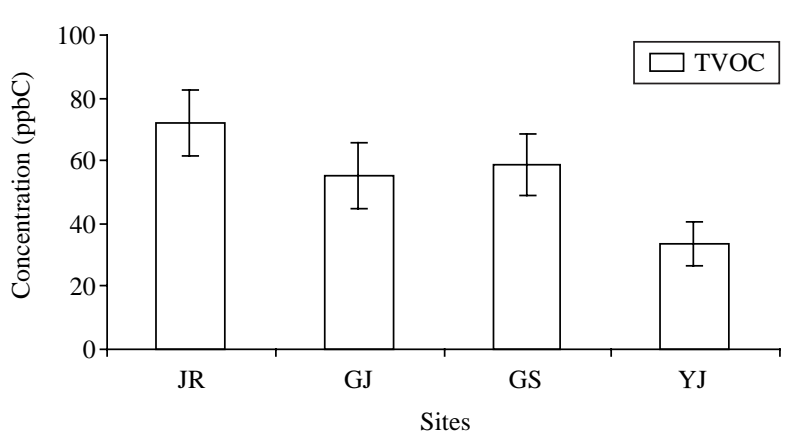

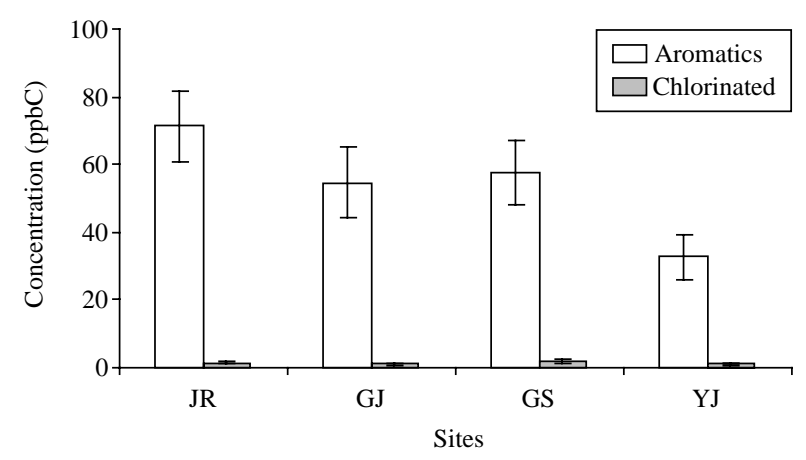

Fig. 2. Ambient concentration of VOC measured at 4 urban residential locations in Seoul.

at YJ. The data presented in Table 3 indicate the dominance of aromatic VOCs at all sites with the highest concentration at JR site $(71.3 \pm 39.9 \mathrm{ppbC})$ and lowest at $\mathrm{YJ}(32.6 \pm 27.9 \mathrm{ppbC})$. Among all these sites, the highest mean concentration (ppbC) of $\Sigma$ BTEX was seen from JR $(69.5 \pm 38.9)$ followed by GS (53.3 \pm 42.1), GJ (55.0 \pm 38.2$)$, and YJ (31.9 \pm 27.7$)$. A summary of individual VOC data shows that the seven VOC species (including benzene, toluene, ethylbenzene, $\mathrm{m} / \mathrm{p}$-xylene, o-xylene, dichlorodifluoromethane, and trichlorofluoromethane) were quantified consistently at all the sampling sites. Because of low abundance of chlorinated VOC data, major aromatic VOCs including BTEX were examined most extensively as the target pollutants of our study. These compounds have been listed as toxic organic pollutants by the United States Environmental Protection Agency (EPA) with adverse effects on human health, as aromatic VOCs can contribute to the formation of photochemical smog (Han and Naeher, 2006). Most Aromatic VOCs can be emitted from fossil fuel combustion, vehicular exhaust, and industrial processes (Ferrari et al., 1998). According to a previous report, the proportion of aromatic VOCs in fossil fuels ranged from 41$51 \%$ and was larger than the paraffins $(28-47 \%)$ and the olefins (7-12\%) (Tsai et al., 2004).

The concentrations of the 20 most abundant species based on the identified VOC at 4 urban locations are 


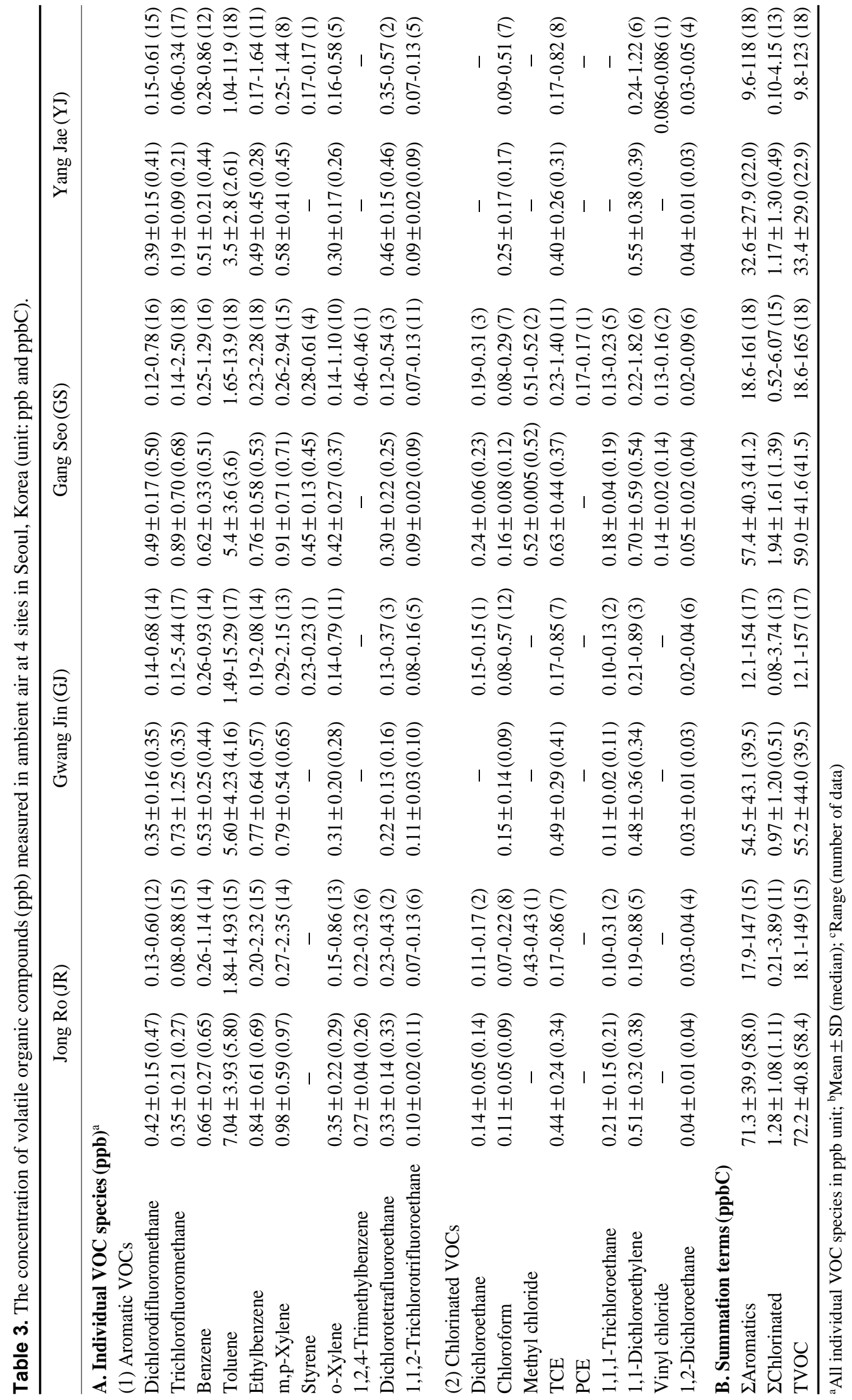




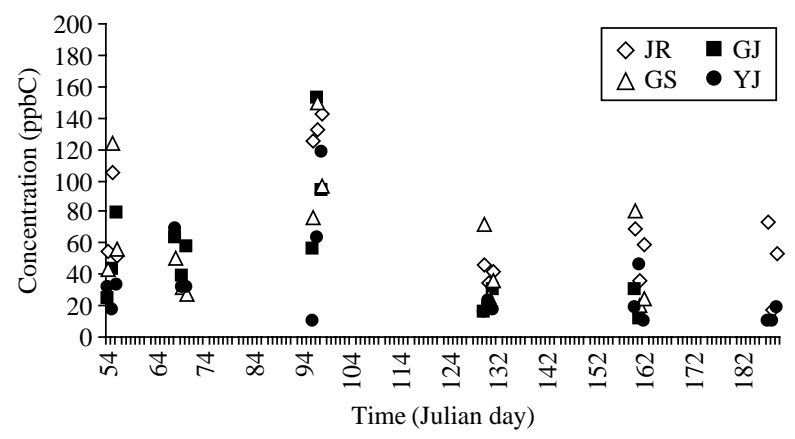

Fig. 3. The concentration of all aromatic VOC ( $\Sigma$ Aromatic (ppbC)) measured at 4 urban sites in Seoul during the study period.

shown in Table 3. Results presented in the Table 3 clearly indicate the dominance of toluene among all the VOC species investigated at all the study sites. The highest concentration of toluene was recorded at JR site with a mean concentration of $7.04 \mathrm{ppb}$ followed by $\mathrm{m}, \mathrm{p}$-xylene $(0.98 \mathrm{ppb})$. In the urban atmosphere, toluene is the most abundant aromatic species, as reported from many of previous studies (Wang and Zhao, 2008; Ho et al., 2004; Kim and Kim, 2002; Kourtidis et al., 2002). The proportions of aromatic VOCs may vary by locations due to differences in traffic and industrial activities, emissions patterns, and meteorological conditions (Lai et al., 2004). The concentration of toluene is typically 2-4 times that of benzene (Borbon et al., 2002; Na and Kim, 2001; Brocco et al., 1997). The mean concentrations of most aromatic VOCs (except toluene) were seen in the range of $0.5-2 \mathrm{ppb}$. It is also noted that BTEX exhibited fairly strong variabilities, as the coefficient of variation $(\mathrm{CV})$ values generally ranged from 40 to $90 \%$.

In Fig. 3, the mean concentrations of aromatic VOCs (mainly BTEX) determined during the study period are compared across 4 sites. The relative dominance of toluene may be accounted for by the effect of traffic activities, as it is used as the major component of gasoline or solvents (Brocco et al., 1997). Due to the high reactivity of toluene and other aromatic hydrocarbons, their presence at high concentration levels can lead to the production of toxic products through atmospheric oxidation (Liu et al., 2000). In addition, benzene is mainly emitted from automobile emissions. Amongst the aromatic hydrocarbons, toluene and benzene are often treated as the main indicators of VOC pollution, while their reactivities are significantly different from each other. Toluene is 5 times more reactive than benzene in its reaction with $\mathrm{OH}$ radicals. Hence, changes in their relative concentration ratio can be used to assess their relative behavior (Gelencsr et al., 1997).
In some previous studies, toluene to benzene (T/B) ratio was computed to infer their source properties (Barletta et al., 2005; Wang et al., 2005; Chan et al., 2002; Lee et al., 2002). Considering that toluene and benzene are the main fuel constituents, T/B ratio can be a useful marker for road traffic emissions (Kelessis et al., 2006; Rappengluck et al., 2005; Brocco et al., 1997; Gelencser et al., 1997). As one good example of such applications, the T/B ratios can be examined as a function of distance to the road (Gelencsr et al., 1997). In this study, the median value of $T / B$ ratios at 4 sites (5.9-9.4) were much higher than those reported in many other urban areas like Rome, Changchum (China), Kaohsiung (Taiwan), and Thessaloniki (Greece) (Hong et al., 2006; Kelessis et al., 2006; Lai et al., 2004; Liu et al., 2000; Brocco et al., 1997). However, these values are rather comparable to those in most of Asian countries such as: Bangkok (10.22), Hong Kong (7.74), and Osaka (7.19) (Lee et al., 2002; Gee and Sollars, 1998; Tsujino and Kuwata, 1993). The higher T/B ratio in the urban air should be associated with highly diversified sources of toluene or with major differences in the fuel and vehicle types (Hoque et al., 2008; Gee and Sollars, 1998).

\subsection{Temporal Variations in VOC Concentration}

Temporal variations in the TVOC concentration and individual VOCs are examined by their daily values at the 4 study sites, as shown in Fig. 4. According to this analysis, the patterns of TVOC and individual VOCs showed good similarities between different sites. TVOC values at all sites peaked in April and then decreased till July. In case of individual VOC, toluene concentration at the JR site recorded the maximum of $14.9 \mathrm{ppb}$ in April, while a vivid dropdown was recognized in July with $1.84 \mathrm{ppb}$.

The seasonal mean values of TVOC and BTEX are also plotted in Fig. 5. TVOC and BTEX species exhibit very clear seasonal characteristics at all study areas. At JR, GJ, and YJ, TVOC showed maximum values during the spring and minimum during summer. However, the pattern of GS was slightly modified with the winter maximum. If the individual VOCs are compared by the seasonal mean values, the results are fairly consistent in most cases (Fig. 5). In many previous studies, seasonal variations in the VOC were generally characterized by high concentration of VOC during winter (Nguyen et al., 2009; Hoque et al., 2008; Na and Kim, 2001; Liu et al., 2000; Brocco et al., 1997). However, there is also contrasting evidence such as higher concentration of aromatic VOC components during summer (Nguyen et al. 2009). Cheng et al. (1997) also reported high concentrations of aromatics in two downtown sites in Edmonton, Canada during 
(a) TVOC

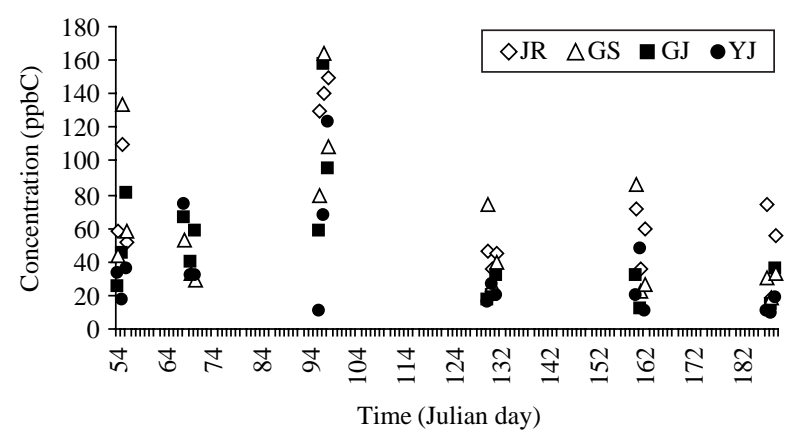

(c) Toluene

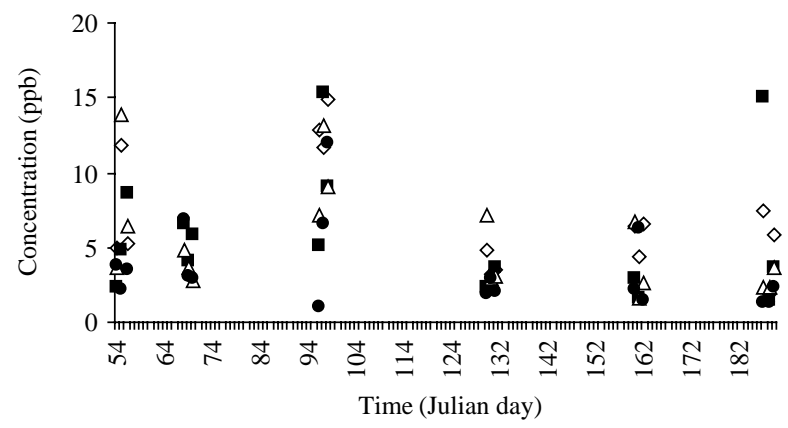

(e) m,p-xylene

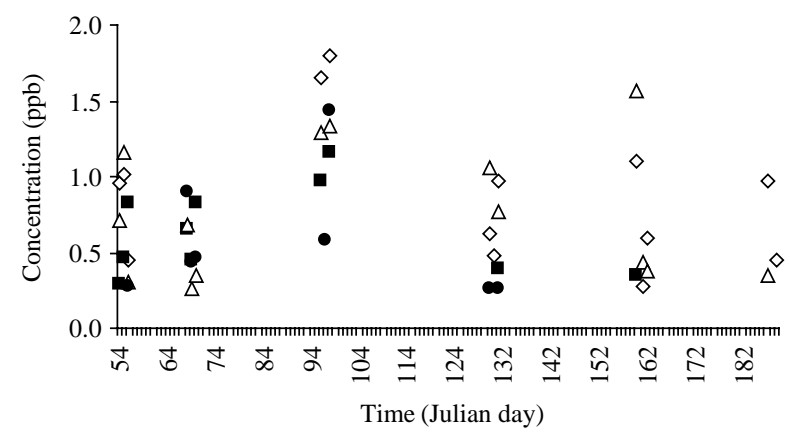

(b) Benzene

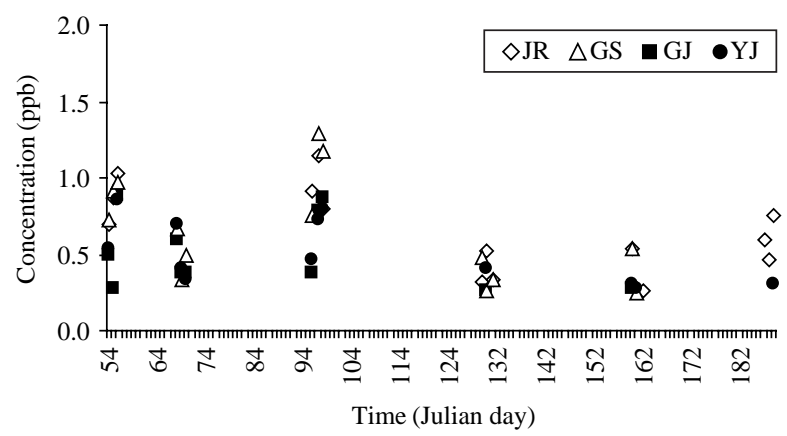

(d) Ethylbenzene

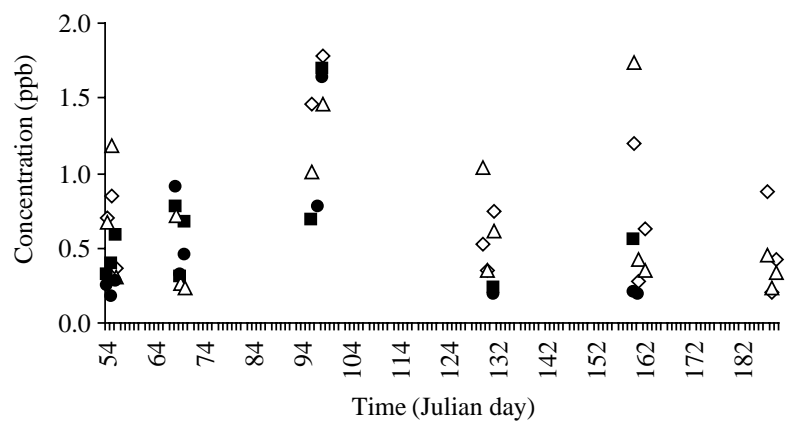

(f) o-xylene

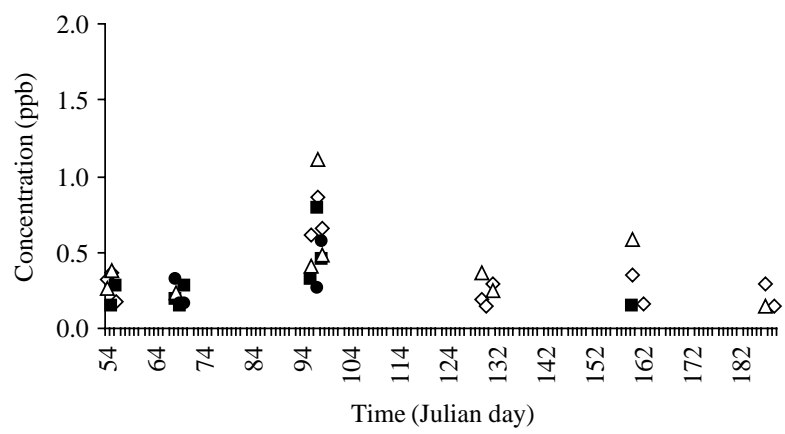

Fig. 4. Temporal variation in the TVOC concentration and five individual components (BTEX) at 4 urban sites in Seoul during the study period.

spring and in the industrial area during winter. Observed seasonal trends can be explained by the combined effects of various factors including variations in source strength and the meteorological conditions. In addition, the availability of $\mathrm{OH}$ radical and/or insolation can also be important, as those factors can influence the efficiency of the removal process of the VOC species from the atmosphere (Singh and Zimmerman, 1992).

\section{3 The Factors Affecting VOC Distributions}

To elucidate the potential roles of different sources controlling the behavior of the aromatic VOCs, corre- lation analysis had been employed by several workers (Hoque et al., 2008; Na and Kim, 2001; Brocco et al., 1997). In this study, correlation analysis was conducted among the concentration data of BTEX, TVOC, criteria pollutants, and meteorological parameters (Table 4). A strong positive correlation was observed between TVOC, $\mathrm{SO}_{2}, \mathrm{NO}_{2}$, and $\mathrm{CO}$ at all the study sites. The cases of the strongest correlation of TVOC were found most abundantly at JR with such variables as with $\mathrm{SO}_{2}$ $(r=0.85, p<0.01)$ or $\mathrm{CO}(r=0.817, p<0.01)$ or $\mathrm{NO}_{2}$ $(r=0.778, p<0.01)$. In accordance with our observations, Smith et al. (2001) suggested that $\mathrm{CO}$ and $\mathrm{SO}_{2}$ 
(a) TVOC

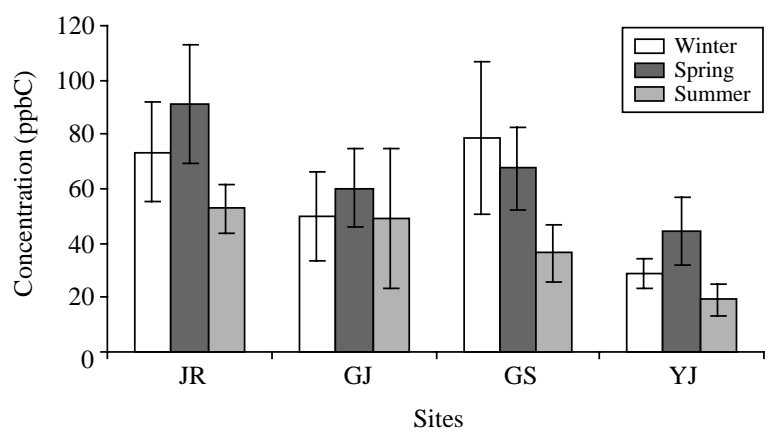

(c) Toluene

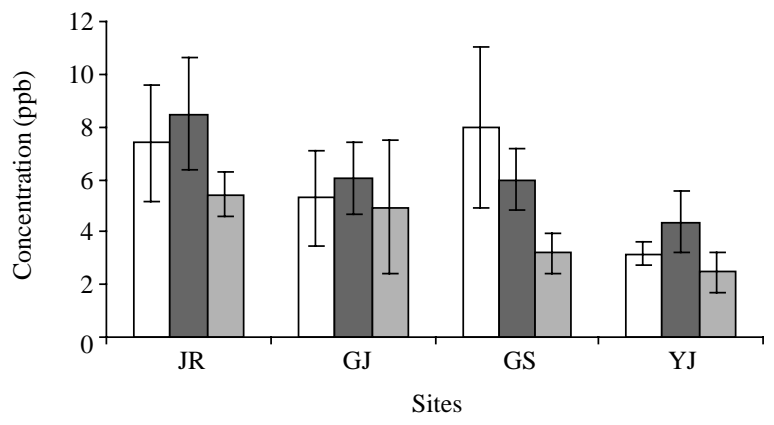

(e) m,p-xylene

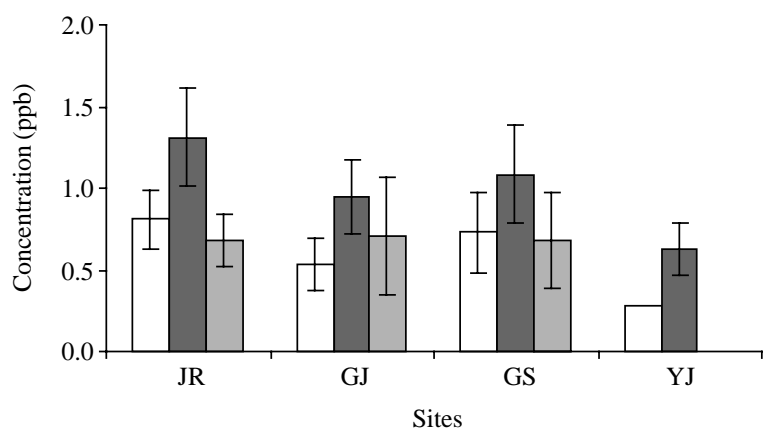

(b) Benzene

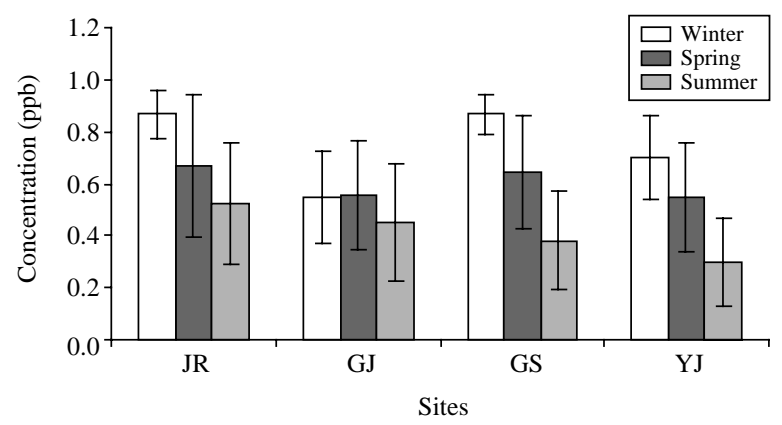

(d) Ethylbenzene

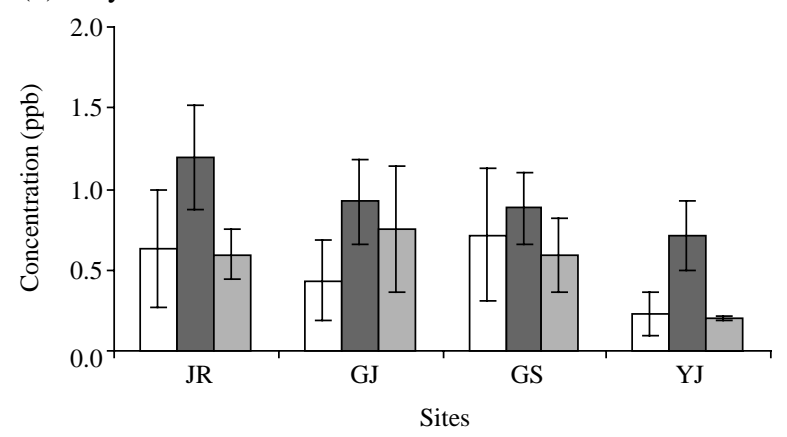

(f) o-xylene

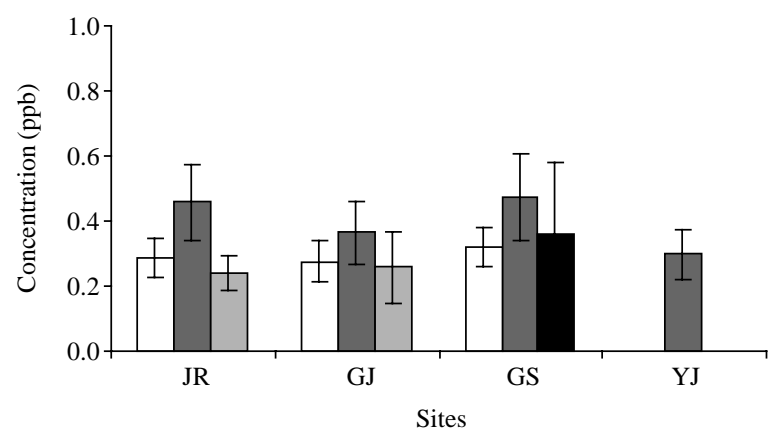

Fig. 5. Seasonal changes in the concentrations of TVOC and individual aromatic VOC at 4 study sites.

should originate from motor vehicles along with $\mathrm{NO}_{\mathrm{x}}$. The existence of strong correlations among most VOC species (e.g., between ethylbenzene and xylene) suggests that they should share the same source properties (Baldasano et al., 1998; Wang et al., 1993). The results also indicate that most meteorological parameters (e.g., wind speed, relative humidity, and air temperature) do not exhibit strong correlations with the VOC concentration data. Benzene, well-known as tracer for automobile exhaust, showed a good correlation $(p<0.01, p<$ 0.05 ) with other VOCs and criteria pollutants at JR, GJ, and GS. However, no such correlation was evident at YJ (Hoque et al., 2008; Hong et al., 2006; Rudd,
1995; Chan et al., 1991). The lack of correlation between benzene and other VOC species in the YJ site suggests that the sources of VOCs in YJ are more complicated in Seoul relative to the other study areas.

\subsection{Comparison of BTEX Levels in Seoul with Previous Studies}

To learn more about the spatial variability or VOC, the average concentrations of BTEX in the four urban locations in Seoul can be evaluated in relation with those measured previously in other urban areas (Nguyen et al., 2009; Wang and Zhao, 2008; Khoder, 2007; Lee et al., 2002; Na and Kim, 2001; Gee and Sollars, 
Table 4. Results of correlation analysis between BTEX compounds, criteria pollutants, and meteorological parameters at four urban locations in Seoul.

\begin{tabular}{|c|c|c|c|c|c|c|c|c|c|c|c|c|c|}
\hline & $\mathrm{B}$ & $\mathrm{T}$ & EB & MPX & OX & TVOC & $\mathrm{SO}_{2}$ & $\mathrm{NO}_{2}$ & $\mathrm{CO}$ & $\mathrm{O}_{3}$ & $\mathrm{~T}$ & RH & WS \\
\hline \multicolumn{14}{|c|}{ (a) Jong Ro } \\
\hline $\mathrm{B}$ & 1 & & & & & & & & & & & & \\
\hline $\mathrm{T}$ & $0.611 *$ & 1 & & & & & & & & & & & \\
\hline EB & $0.535^{*}$ & $0.816 * *$ & 1 & & & & & & & & & & \\
\hline MPX & 0.53 & $0.787 * *$ & $0.985^{* *}$ & 1 & & & & & & & & & \\
\hline OX & $0.607 *$ & $0.807 * *$ & $0.977 * *$ & $0.994 * *$ & 1 & & & & & & & & \\
\hline TVOC & $0.65^{*}$ & $0.979 * *$ & $0.908 * *$ & $0.899 * *$ & $0.913 * *$ & 1 & & & & & & & \\
\hline $\mathrm{SO}_{2}$ & $0.584 *$ & $0.845^{* *}$ & $0.715 * *$ & $0.778 * *$ & $0.795^{* *}$ & $0.852 * *$ & 1 & & & & & & \\
\hline $\mathrm{NO}_{2}$ & 0.467 & $0.686^{* *}$ & $0.844 * *$ & $0.892 * *$ & $0.881 * *$ & $0.778 * *$ & $0.822 * *$ & 1 & & & & & \\
\hline $\mathrm{CO}$ & $0.587 *$ & $0.733 * *$ & $0.859 * *$ & $0.909 * *$ & $0.921 * *$ & $0.817 * *$ & $=0.862 * *$ & $0.958 * *$ & 1 & & & & \\
\hline $\mathrm{O}_{3}$ & -0.182 & 0.054 & -0.058 & -0.093 & 0.036 & -0.018 & -0.007 & -0.149 & -0.176 & 1 & & & \\
\hline Temp & -0.237 & -0.021 & 0.136 & 0.182 & 0.172 & -0.006 & 0.071 & 0.238 & 0.217 & 0.432 & 1 & & \\
\hline $\mathrm{RH}$ & -0.437 & -0.367 & -0.375 & -0.393 & -0.394 & -0.416 & -0.319 & -0.293 & -0.255 & -0.152 & 0.369 & 1 & \\
\hline WS & -0.366 & -0.204 & -0.427 & $-0.56^{*}$ & -0.469 & -0.311 & -0.382 & $-0.56 *$ & $-0.618 * *$ & $0.636 * *$ & -0.128 & -0.099 & 1 \\
\hline
\end{tabular}

(b) Gwang Jin

\begin{tabular}{|c|c|c|c|c|c|c|c|c|c|c|c|}
\hline $\bar{B}$ & 1 & & & & & & & & & & \\
\hline $\mathrm{T}$ & $0.83 * *$ & 1 & & & & & & & & & \\
\hline $\mathrm{EB}$ & $0.72 * *$ & $0.927 * *$ & 1 & & & & & & & & \\
\hline MPX & $0.767 * *$ & $0.929 * *$ & $0.921 * *$ & 1 & & & & & & & \\
\hline OX & $0.723^{*}$ & $0.89 * *$ & $0.918 * *$ & $0.99 * *$ & 1 & & & & & & \\
\hline TVOC & $0.838 * *$ & $0.997 * *$ & $0.948 * *$ & $0.947 * *$ & $0.914 * *$ & 1 & & & & & \\
\hline $\mathrm{SO}_{2}$ & $0.537 *$ & $0.483 *$ & 0.497 & 0.504 & 0.471 & $0.521 *$ & 1 & & & & \\
\hline $\mathrm{NO}_{2}$ & 0.511 & $0.543^{*}$ & $0.62 *$ & $0.626^{*}$ & $0.796^{* *}$ & $0.573^{*}$ & $0.772 * *$ & 1 & & & \\
\hline $\mathrm{CO}$ & 0.396 & $0.505^{*}$ & $0.641 *$ & $0.614 *$ & $0.707 *$ & $0.544^{*}$ & $0.565^{*}$ & $0.754 * *$ & 1 & & \\
\hline $\mathrm{O}_{3}$ & 0.009 & -0.079 & 0.232 & 0.243 & 0.134 & -0.061 & -0.119 & -0.33 & 0.035 & 1 & \\
\hline Temp & -0.12 & 0.043 & 0.251 & 0.208 & 0.269 & 0.065 & -0.22 & 0.016 & 0.42 & $0.602 * *$ & 1 \\
\hline $\mathrm{RH}$ & -0.239 & -0.22 & -0.09 & -0.207 & -0.191 & -0.217 & $-0.511 *$ & -0.342 & 0.19 & 0.199 & $0.593 * * \quad 1$ \\
\hline WS & 0.043 & -0.08 & 0.042 & 0.061 & -0.13 & -0.106 & -0.035 & -0.277 & -0.382 & $0.567 *$ & -0.281 \\
\hline
\end{tabular}

(c) Gang Seo

\begin{tabular}{|c|c|c|c|c|c|c|c|c|c|c|c|c|}
\hline B & 1 & & & & & & & & & & & \\
\hline $\mathrm{T}$ & $0.808 * *$ & 1 & & & & & & & & & & \\
\hline $\mathrm{EB}$ & $0.677 * *$ & $0.807 * *$ & 1 & & & & & & & & & \\
\hline MPX & $0.647 *$ & $0.772 * *$ & $0.965 * *$ & 1 & & & & & & & & \\
\hline $\mathrm{OX}$ & $0.704 *$ & $0.708 *$ & $0.954 * *$ & $0.995 * *$ & 1 & & & & & & & \\
\hline TVOC & $0.832 * *$ & $0.975 * *$ & $0.908 * *$ & $0.889 * *$ & $0.847 * *$ & 1 & & & & & & \\
\hline $\mathrm{SO}_{2}$ & $0.622 *$ & 0.453 & $0.501 *$ & 0.47 & 0.335 & $0.521 *$ & 1 & & & & & \\
\hline $\mathrm{NO}_{2}$ & $0.718 * *$ & $0.517 *$ & $0.597 * *$ & $0.624 *$ & 0.55 & $0.615^{* *}$ & $0.774 * *$ & 1 & & & & \\
\hline $\mathrm{CO}$ & 0.406 & 0.291 & 0.23 & 0.231 & 0.291 & 0.322 & 0.29 & $0.575^{*}$ & 1 & & & \\
\hline $\mathrm{O}_{3}$ & -0.301 & -0.384 & -0.285 & -0.188 & -0.039 & -0.369 & 0.155 & -0.325 & $-0.513^{*}$ & 1 & & \\
\hline Temp & -0.247 & -0.212 & 0.092 & 0.31 & 0.144 & -0.129 & 0.023 & 0.022 & $-0.511 *$ & 0.358 & 1 & \\
\hline RH & -0.308 & -0.006 & 0.149 & 0.123 & -0.18 & -0.004 & -0.421 & -0.36 & -0.398 & -0.109 & 0.468 & 1 \\
\hline WS & $-0.638 * *$ & -0.447 & -0.378 & -0.401 & -0.392 & $-0.469 *$ & -0.248 & $-0.633 * *$ & $-0.609 * *$ & $0.736 * *$ & 0.252 & 0.292 \\
\hline
\end{tabular}

(d) Yang Jae

\begin{tabular}{|c|c|c|c|c|c|c|c|c|c|c|c|c|c|}
\hline B & 1 & & & & & & & & & & & & \\
\hline $\mathrm{T}$ & 0.566 & 1 & & & & & & & & & & & \\
\hline EB & 0.596 & $0.907 * *$ & 1 & & & & & & & & & & \\
\hline MPX & 0.347 & $0.965 * *$ & $0.984 * *$ & 1 & & & & & & & & & \\
\hline $\mathrm{OX}$ & 0.827 & $0.987^{* *}$ & $0.995 * *$ & $0.989 * *$ & 1 & & & & & & & & \\
\hline TVOC & $0.640 *$ & $0.989 * *$ & $0.960 * *$ & $0.969 * *$ & $0.988 * *$ & 1 & & & & & & & \\
\hline $\mathrm{SO}_{2}$ & 0.448 & 0.417 & $0.873 * *$ & $0.861 * *$ & $0.906^{*}$ & 0.465 & 1 & & & & & & \\
\hline $\mathrm{NO}_{2}$ & 0.520 & $0.500^{*}$ & $0.703^{*}$ & 0.599 & 0.646 & $0.553^{*}$ & $0.654 * *$ & 1 & & & & & \\
\hline $\mathrm{CO}$ & $0.596 *$ & $0.516^{*}$ & $0.619 *$ & 0.52 & 0.49 & $0.560^{*}$ & $0.738 * *$ & $0.902 * *$ & $\quad 1$ & & & & \\
\hline $\mathrm{O}_{3}$ & -0.391 & -0.074 & -0.03 & 0.375 & 0.487 & -0.14 & 0.111 & -0.392 & -0.374 & 1 & & & \\
\hline Temp & -0.366 & 0.092 & 0.362 & 0.464 & 0.757 & 0.037 & 0.002 & 0.189 & -0.06 & $0.488 *$ & 1 & & \\
\hline $\mathrm{RH}$ & -0.543 & -0.344 & -0.421 & -0.272 & 0.318 & -0.422 & $-0.506^{*}$ & -0.379 & -0.466 & 0.116 & 0.41 & 1 & \\
\hline WS & -0.113 & 0.079 & -0.2 & -0.101 & -0.341 & 0.044 & -0.185 & $-0.559 *$ & -0.431 & 0.431 & -0.152 & -0.23 & 1 \\
\hline
\end{tabular}

* Correlation is significant at the 0.05 level; ** Correlation is significant at the 0.01 level 


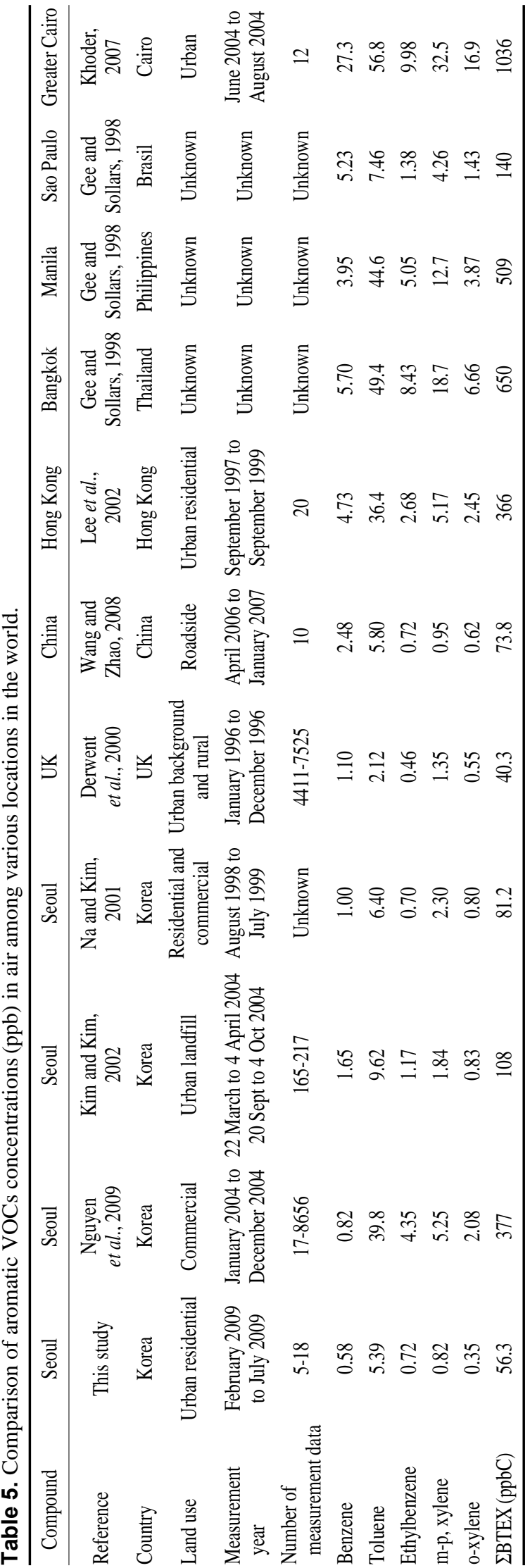

1998). In order to assess the relative dominance of BTEX, their concentration data were collected from different studies and compared in Table 5. To facilitate this comparison, the original data for aromatic VOCs (mainly BTEX) reported in other studies (in ppb unit) were also bound together for the derivation of $\Sigma$ BTEX (ppbC). The concentration of $\Sigma \mathrm{BTEX}$ measured in this study (56.3 ppbC) was higher than that of UK (40.3 $\mathrm{ppbC}$ ) but significantly smaller than others such as Cairo, Thailand, Philippines, Hong Kong, and China. The $\Sigma$ BTEX levels (ppbC) can also be compared on the basis of the land use type. The highest mixing ratio of the $\Sigma$ BTEX was 1,036 ppbC in Cairo(Khoder, 2007), while the lowest value ( $40.3 \mathrm{ppbC}$ ) was recorded in 12 cities in UK (Derwent et al., 2000). The results of this study are lower by a factor of 1.4 times than previous one measured in other locations of Seoul ( $\mathrm{Na}$ and Kim, 2001) and 6.5 times than those of Hong Kong (Lee et al., 2002).

A comparison of the individual BTEX component indicated that toluene levels were consistently the highest of all VOC in all the studies (Table 5). As shown in Table 5, the concentration of benzene and toluene was low compared to the previous studies conducted in Seoul (Nguyen et al., 2009; Kim and Kim, 2002; $\mathrm{Na}$ and Kim, 2001). If the toluene data are compared with those seen in the other Asian cities, our values appear to be most comparable to that of China (5.80 ppb) (Wang and Zhao, 2008). However, our data are lower by 1-9 times than those measured previously in Seoul (Nguyen et al., 2009; Kim and Kim, 2002; Na and Kim, 2001) as well as other Asian cities like Hong Kong (Lee et al., 2002) and Thailand/Philippines (Gee and Sollars, 1998). The concentration level of toluene in the present study (5.39 ppb) is however still much higher than that of UK (2.12 ppb, Derwent et al., 2000) but was lower than that reported from Sao Paulo (7.46 ppb, Gee and Sollars, 1998) and Greater Cairo (56.8 ppb, Khoder, 2007). It is also interesting to note that benzene levels were lower by 1.4-2.8 times than those measured previously in Seoul (Nguyen et al., 2009; Kim and Kim, 2002; Na and Kim, 2001). Our findings of generally reduced BTEX levels relative to previous studies in Seoul may reflect the effect of the stringent regulations enforced by the Korean government, e.g., less than $2 \%$ of benzene in gasoline fuel $(\mathrm{Na}$ et al., 2002).

\subsection{VOC Pollution and Human Exposure}

As the major components of aromatics, BTEX are well known for toxic and carcinogenic health effects. The concentration data of BTEX measured in this study were compared with those set by current regulations, advisories, and guidelines, as recommended in a 
Table 6. Regulations and guidelines for volatile organic compounds by international and national agencies.

\begin{tabular}{|c|c|c|c|c|c|c|c|c|c|}
\hline \multirow{4}{*}{ Compound } & \multicolumn{9}{|c|}{ Regulations and guidelines ${ }^{\mathrm{a}}(\mathrm{ppm})$} \\
\hline & \multirow{3}{*}{$\begin{array}{l}\text { AQG } \\
\text { WHO }\end{array}$} & \multicolumn{2}{|c|}{ Inhalation MRL } & \multirow{3}{*}{$\begin{array}{c}\text { TLV } \\
\text { ACGIH }\end{array}$} & \multirow{2}{*}{\multicolumn{2}{|c|}{ STEL }} & \multirow{3}{*}{$\frac{\begin{array}{c}\text { REL } \\
(10-h \text { TWA })\end{array}}{\text { NIOSH }}$} & \multirow{3}{*}{$\begin{array}{c}\begin{array}{c}\text { PEL } \\
(8-h \text { TWA })^{\mathrm{b}}\end{array} \\
\text { OSHA }\end{array}$} & \multirow{3}{*}{$\begin{array}{c}\text { IDLH } \\
\text { NIOSH }\end{array}$} \\
\hline & & \multirow{2}{*}{$\begin{array}{c}\text { Acute } \\
\text { ATSDR }\end{array}$} & \multirow{2}{*}{$\begin{array}{l}\text { Chronic } \\
\text { ATSDR }\end{array}$} & & & & & & \\
\hline & & & & & ACGIH & $\mathrm{NIOSH}$ & & & \\
\hline B & $6 \times 10^{-6}$ & 0.009 & 0.003 & 0.5 & 2.5 & 1.0 & 0.1 & 1.0 & 500 \\
\hline $\mathrm{T}$ & & 1.0 & 0.08 & 50 & & 150 & 100 & 200 & \\
\hline EB & & 10 & 0.3 & 100 & 125 & $125^{\mathrm{c}}$ & 100 & 100 & 800 \\
\hline $\mathrm{X}$ & & 2.0 & 0.05 & 100 & 151 & 151 & $100^{\mathrm{d}}$ & 100 & 900 \\
\hline STY & 0.016 & 2.0 & 0.2 & 20 & 40 & 100 & 50 & 100 & 686 \\
\hline $\mathrm{MC}$ & & 0.5 & 0.05 & & & & & 100 & \\
\hline 1,1-DCE & & & & 200 & 250 & & & 99 & 4,000 \\
\hline $\mathrm{CF}$ & & 0.1 & 0.02 & & & & & 50 & \\
\hline TCE & 25.12 & 2.0 & & & & & & 100 & \\
\hline PCE & & 0.2 & 0.04 & & & & & 100 & \\
\hline 1,1-DCEY & & & & & & & & 1.0 & \\
\hline VC & 0.0004 & 0.5 & & 1.0 & & & & 1.0 & \\
\hline 1,2-DCE & & & & 10 & & 2.0 & 1.0 & 50 & 50 \\
\hline $1,1,1-\mathrm{TCE}$ & & 2.0 & & 350 & 450 & & 350 & 350 & 700 \\
\hline
\end{tabular}

aDefinitions for acronyms: AQG: air quality guideline; TLV: threshold limit values; STEL: short-term exposure limit; REL: recommended exposure limit; PEL: permissible exposure limit; IDLH: immediately dangerous to life or health; TWA: time-weighted average, ${ }^{b}$ For general industry, ${ }^{\mathrm{c}} 15$-minute TWA, ${ }^{\mathrm{d}} 15$-minute ceiling limit

number of reports made by the US-Agency for Toxic Substances and Disease Registry (ATSDR) (Table 6). Because all our measurements were made in the urban ambient air, our data should be significantly lower than those regulation values such as: (1) the World Health Organization air quality guideline (WHO AQG), (2) the threshold limit values (TLV) set by the American Conference of Governmental Industrial Hygienists (ACGIH), (3) the recommended exposure limits (REL) of the National Institute for Occupational Safety and Health (NIOSH), (4) the permissible exposure limits (PEL) set by the Occupational Safety and Health Administration (OSHA), and (5) immediately dangerous to life or health (IDLH) value of NIOSH. It should be more meaningful to compare with such criteria as the national air quality standard of benzene (1.54 ppb) in Korea, although our benzene data measured at all study sites were still well below such criterion. Our benzene data are however found to be higher than the criteria established by the WHO in which a lifetime exposure of $1 \mu \mathrm{g} \mathrm{m}^{-3}(0.31 \mathrm{ppb})$ of carcinogenic benzene can lead to about six cases of leukemia per million inhabitants (WHO, 1999). Thus, in a city like Seoul with a population of about 10.3 million and an average benzene level of $1.85 \mu \mathrm{g} \mathrm{m}^{-3}(0.57 \mathrm{ppb})$, one may expect about 114 cases of leukemia in the city. It is thus necessary to apply pollution control measures on VOC emission in the city by considering the toxic health effects caused due to benzene.

\section{CONCLUSIONS}

To assess the level of VOC pollution in Seoul, samples were collected for VOC analysis for 3 consecutive days per month basis from February 2009 to July 2009. In this study, a total of 20 VOCs (11 aromatic and 9 chlorinated species) were measured at the 4 urban residential locations in Seoul, Korea. The TVOC concentration was recorded to be the highest at JR (72.2 $\mathrm{ppbC})$ and lowest at $\mathrm{YJ}(33.4 \mathrm{ppbC})$. Among the BTEX components, toluene consistently showed the maximum at all the sites with the highest mean value at JR (7.04 $\mathrm{ppb}$ ), while the lowest value was found from 1,2-dichlorethane at GJ $(0.03 \mathrm{ppb})$.

If the temporal variation is examined using the TVOC and individual BTEX data, the results showed large similarities with the maximum concentration typically occurring on the Julian days 95-97 at all the sites. Examination of the seasonal data sets indicated that TVOC concentration generally peaked during spring at JR, GJ, and YJ site, whereas those in the GS site peaked during winters. The concentration of toluene tended to peak during spring at JR, GJ, and YJ site, whereas winter time peak was noticed in the GS site. In contrast, benzene generally recorded maximum concentration during winter at all the sites. The results of correlation analysis at JR, GJ, and GS site indicated strongly correlated cases of benzene with TVOC and other VOCs, while it showed strong correlation with 
TVOC at YJ.

If a comparison of the VOC data is made mainly in terms of BTEX levels between different studies, the emissions due to automobile exhaust and evaporative losses appeared to be the main cause for the high concentration of VOCs in certain countries. The results of the present study suggest that vehicular emissions should have contributed to the VOC pollution at all the study sites. Considering the importance of VOC pollution in the urban environment, much more elaborated efforts are needed to place limits on VOC distribution, particularly aromatic hydrocarbons among the hazardous air pollutants.

\section{ACKNOWLEDGEMENTS}

This work was supported by the National Research Foundation of Korea (NRF) grant funded by the Miistry of Education, Science and Technology (MEST) (No. 2009-0093848).

\section{REFERENCES}

Abrantes, R.D., de Assuncao, J.V., Pesquero, C.R. (2004) Emission of polycyclic aromatic hydrocarbons from light-duty diesel vehicles exhaust. Atmospheric Environment 38, 1631-1640.

Anthwal, A., Jung, K., Kim, H.J., Bae, I.-S., Kim, K.H. Polycyclic aromatic hydrocarbons in ambient air at four urban locations in Seoul, Korea. Fresenius Environmental Bulletin In Press.

Appel, B.R., Tokiwa, Y., Hsu, J., Kothny, E.L., Hahn, E. (1985) Visibility as related to atmospheric aerosol constituents. Atmospheric Environment 19, 1525-1534.

Atkinson, R. (2000) Atmospheric chemistry of VOCs and $\mathrm{NO}_{\mathrm{x}}$. Atmospheric Environment 34, 2063-2101.

Baldasano, J.M., Delgado, R., Calbó, J. (1998) Applying receptor models to analyze urban/suburban VOCs air quality in Martorell (Spain). Environmental Science and Technology 32, 405-412.

Barletta, B., Meinardi, S., Rowl, F.S., Chan, C., Wang, X., Zou, S., Chan, L.Y., Blake, D. (2005) Volatile organic compounds in 43 Chinese cities. Atmospheric Environment 39, 5979-5990.

Barletta, B., Meinardi, S., Simpson, I.J., Khwaja, H.A., Blake, D.R., Rowland, F.S. (2002) Mixing ratios of volatile organic compounds (VOCs) in the atmosphere of Karachi, Pakistan. Atmospheric Environment 36, 3429-3443.

Borbon, A., Locoge, N., Veillerot, M., Galloo, J.C., Guillermo, R. (2002) Characteristics of NMHCs in a French urban atmosphere: overview of the main sources. The Science of the Total Environment 292, 177191.
Brocco, D., Fratarcangeli, R., Lepore, L., Petricca, M., Ventrone, I. (1997) Determination of aromatic hydrocarbons in urban air of Rome. Atmospheric Environment 31, 557-566.

Broderick, B.M., Marnane, I.S. (2002) A comparison of the C2-C9 hydrocarbon compositions of vehicle fuels and urban air in Dublin, Ireland. Atmospheric Environment 36, 975-986.

Chan, C.C., Spengler, J.D., Ozkaynak, H., Lefkoulou, M. (1991) Commuter exposure to volatile organic compounds in Boston, Massachusetts. Journal of Air and Waste Management 41, 1594-1600.

Chan, C.Y., Chan, L.Y., Wang, X.M., Liu, Y.M., Lee, S.C., Zou, S.C., Sheng, G.Y., Fu, J.M. (2002) Volatile organic compounds in roadside microenvironments of metropolitan Hong Kong. Atmospheric Environment, 36, 2039-2047.

Cheng, L., Fu, L., Angle, R.P., Sandhu, H.S. (1997) Seasonal variations of volatile organic compounds in Edmonton, Alberta. Atmospheric Environment 31, 239246.

City of Seoul (2010) http://english.seoul.go.kr/gtk/about/ fact.php.

Cocker, III D.R., Mader, B.T., Kalberer, M., Flagan, R.C., Seinfeld, J.H. (2001) The effect of water on gasparticle partitioning of secondary organic aerosol: II. $\mathrm{m}$-xylene and 1,3,5-trimethylbenzene photooxidation systems. Atmospheric Environment 35, 6073-6085.

Derwent, R.J., Davies, T.J., Delaney, M., Dollard, G.J., Field, R.A., Dumitrean, P., Nason, P.D., Jones, B.M.R., Pepler, S.A. (2000) Analysis and interpretation of the continuous hourly monitoring data for $26 \mathrm{C} 2-\mathrm{C} 8$ hydrocarbons at 12 United Kingdom sites during 1996. Atmospheric Environment 34, 297-312.

Ferrari, C.P., Kaluzny, P., Roche, A., Jacob, V., Poster, P. (1998) Aromatic hydrocarbons and aldehydes in the atmosphere of Grenoble, France. Chemosphere 37, 1587-1601.

Gee, I.L., Sollars, C.J. (1998) Ambient air levels of volatile organic compounds in Latin American and Asian cities. Chemosphere 36, 2497-2506.

Gelencsr, A., Siszler, K., Hlavay, J. (1997) Toluene-benzene concentration ratio as a tool for characterizing the distance from vehicular emission sources. Environmental Science and Technology 31, 2869-2872.

Guo, H., Wang, T., Simpson, I.J., Blake, D.R., Yu, X.M., Kwok, Y.H., Li, Y.S. (2004) Source contributions to ambient VOCs and CO at a rural site in eastern China, Atmospheric Environment 38, 4551-4560.

Han, X., Naeher, L.P. (2006) A review of traffic-related air pollution exposure assessment studies in the developing world, Environment International 32(1), 106-120.

Ho, K.F., Lee, S.C., Guo, H., Tsai, W.Y. (2004) Seasonal and diurnal variations of volatile organic compounds (VOCs) in the atmosphere of Hong Kong. Science of the Total Environment 322, 155-166.

Hong, Y.J., Jeng, H.A., Gau, Y.Y., Lin, C., Lee, I.L. (2006) Distribution of volatile organic compounds in 
ambient air of Kaohsiung, Taiwan. Environmental Monitoring and Assessment 119, 43-56.

Hoque, R.R., Khillare, P.S., Agarwal, T., Shridhar, V., Balachandran, S. (2008) Spatial and temporal variation of BTEX in the urban atmosphere of Delhi, India. Science of the Total Environment 392, 30-40.

Kelessis, A.G., Petrakakis, M.J., Zoumakis, N.M. (2006) Determination of benzene, toulene, ethylbenzene, and xylenes in the urban air of Thessaloniki, Greece. Environmental Toxicology 21(4), 440-443.

Khoder, M.I. (2007) Ambient levels of volatile organic compounds in the atmosphere of Greater Cairo. Atmospheric Environment 41, 554-566.

Kim, K.H., Kim, M.Y. (2002) The distributions of BTEX compounds in the ambient atmosphere of the Nan-JiDo abandoned landfill site in Seoul. Atmospheric Environment 36, 2433-2446.

Kim, Y.M., Harrad, S., Harrison, R.M. (2001) Concentrations and sources of VOCs in urban domestic and public microenvironments. Environmental Science and Technology 35, 997-1004.

Kourtidis, K., Ziomas, I., Zerefos, C., Kosmidis, E., Symeonidis, P., Christophilopoulos, E., Karathanassis, S., Mploutsos, A. (2002) Benzene, toluene, $\mathrm{O}_{3}, \mathrm{NO}_{2}$ and $\mathrm{SO}_{2}$ measurements in an urban street canyon in Thessaloniki, Greece. Atmospheric Environment 36, 53555364.

Lai, C.H., Chen, K.S., Ho, Y.T., Chou. M.S. (2004). Characteristics of $\mathrm{C}_{2}-\mathrm{C}_{15}$ hydrocarbons in the air of Urban Kaohsiung, Taiwan. Atmospheric Environment 38, 1997-2011.

Lee, S.C., Chiu, M.Y., Ho, K.F., Zou, S.C., Wang, X. (2002) Volatile organic compounds (VOCs) in urban atmosphere of Hong Kong. Chemosphere 48, 375-382.

Liu, C., Xu, Z., Du, Y., Guo, H. (2000) Analyses of volatile organic compounds concentrations and variation trends in the air of Changchun, the northeast of China. Atmospheric Environment 34, 4459-4466.

Na, K., Kim, Y.P. (2001) Seasonal characteristics of ambient volatile organic compounds in Seoul, Korea. Atmospheric Environment 35, 2603-2614.

Nguyen, H.T., Kim, K.H., Kim, M.Y. (2009) Volatile organic compounds at an urban monitoring station in Korea. Journal of Hazardous Materials 161, 163-174.

Odum, J.R., Jungkamp, T.P.W., Griffin, R.J., Forstner, H.J.L., Flagan, R.C., Seinfeld, J.H. (1997) Aromatics, reformulated gasoline, and atmospheric organic aerosol formation. Environmental Science and Technology 31, 1890-1897.

Rappengluck, B., Schmitz, R., Bauerfeind, M., CeredaBalic, F., von Baer, D., Jorquera, H., Silva, Y., Oyola, P. (2005) An urban photochemistry study in Santiago de Chile. Atmospheric Environment 39, 2913-2931.

Rudd, H.J. (1995) Emissions of Volatile Organic Compounds from Stationary Sources in the United Kingdom:
Speciation, AEA Technology Report, AEA/CS/16419033/REMA029/Issue 2, NETCEN, Culham Laboratory, Oxfordshire.

Seaton, A., MacNee, W., Donaldson, K., Godden, D. (1995) Particulate air pollution and acute health effects. The Lancet 345, 176-178.

Singh, H.B., Zimmerman, P.B. (1992) Atmospheric distributions and sources of nonmethane hydrocarbons. In Gaseous Pollutants: Characterization and Cycling (Nriagu, J.O. Ed), Wiley, New York, USA, pp. 177-225.

Smith S., Stribley, F.T., Milligan, P., Barratt, B. (2001) Factors influencing measurements of $\mathrm{PM}_{10}$ during 1995-1997 in London. Atmospheric Environment 35, 4651-4662.

Srivastavaa, A., Joseph, A.E., Devotta, S. (2006) Volatile organic compounds in ambient air of Mumbai-India. Atmospheric Environment 40, 892-903.

Tavares, M. Jr., Pinto, J.P., Souza, A.L., Scarminio, I.S., Solci, M.C. (2004) Emission of polycyclic aromatic hydrocarbons from diesel engine in a bus station, Londrina, Brazil, Atmospheric Environment 38, 5039-5044.

Tsai, J.H., Hsu, Y.C., Yang, J.Y. (2004) The relationship between volatile organic profiles and emission sources in ozone episode region-a case study in Southern Taiwan. Science of the Total Environment 328, 131-142.

Tsujino, Y., Kuwata, K. (1993) Sensitive flame ionization detector for the determination of trace of atmospheric hydrocarbons by capillary gas chromatography. Journal of Chromatography 642, 383-388.

US EPA (1993) Integrated Risk Information System (IRIS) on Benzene, Environmental Criteria and Assessment Office, Office of Health and Environmental Assessment, Office of Research and Development, Cincinnati, $\mathrm{OH}$.

Wang, X.M., Sheng, G.Y., Fum, J.M., Chan, C.Y., Lee, S.C., Chan, L.Y., Wang, Z.S. (1993) Urban roadside aromatic hydrocarbons in three cities of the Pearl River Delta, People's Republic of China. Atmospheric Environment 36, 5141-5148.

Wang, P., Zhao, W. (2008) Assessment of ambient volatile organic compounds (VOCs) near major roads in urban Nanjing, China. Atmospheric Research 89, 289297.

Wang, T., Guo, H., Blake, D.R., Kwok, Y.H., Simpson, I.J., Li, Y.S. (2005) Measurements of trace gases in the inflow of South China sea background air and outflow of regional pollution at Tai O, Southern China. Journal of Atmospheric Chemistry 52, 295-317.

World Health Organization (WHO) (1999) Air Quality Guidelines for Europe. WHO Regional Publication, European Series. World Health Organization. Regional Office for Europe, Copenhagen.

(Received 30 March 2010, accepted 7 May 2010) 